\title{
Malaria parasite species composition of Plasmodium infections among asymptomatic and symptomatic school-age children in rural and urban areas of Kinshasa, Democratic Republic of Congo
}

Sabin S. Nundu ${ }^{1,2,3,4}$, Richard Culleton ${ }^{5^{*}}$, Shirley V. Simpson ${ }^{1,2,3}$, Hiroaki Arima ${ }^{1,2}$, Jean-Jacques Muyembe ${ }^{4}$, Toshihiro Mita ${ }^{6}$, Steve Ahuka ${ }^{4}$ and Taro Yamamoto 1,2,3

\begin{abstract}
Background: Malaria remains a major public health concern in the Democratic Republic of Congo (DRC), and school-age children are relatively neglected in malaria prevalence surveys and may constitute a significant reservoir of transmission. This study aimed to understand the burden of malaria infections in school-age children in Kinshasa/DRC.

Methods: A total of 634 (427 asymptomatic and 207 symptomatic) blood samples collected from school-age children aged 6 to 14 years were analysed by microscopy, RDT and Nested-PCR.

Results: The overall prevalence of Plasmodium spp. by microscopy, RDT and PCR was 33\%, 42\% and $62 \%$ among asymptomatic children and 59\%,64\% and 95\% in symptomatic children, respectively. The prevalence of Plasmodium falciparum, Plasmodium malariae and Plasmodium ovale spp. by PCR was 58\%, 20\% and $11 \%$ among asymptomatic and $93 \%, 13 \%$ and $16 \%$ in symptomatic children, respectively. Among P. ovale spp., P. ovale curtisi, P. ovale wallikeri and mixed P. ovale curtisi $+P$. ovale wallikeri accounted for $75 \%, 24 \%$ and $1 \%$ of infections, respectively. All Plasmodium species infections were significantly more prevalent in the rural area compared to the urban area in asymptomatic infections $(p<0.001)$. Living in a rural as opposed to an urban area was associated with a five-fold greater risk of asymptomatic malaria parasite carriage ( $p<0.001)$. Amongst asymptomatic malaria parasite carriers, $43 \%$ and $16 \%$ of children harboured mixed Plasmodium with P. falciparum infections in the rural and the urban areas, respectively, whereas in symptomatic malaria infections, it was $22 \%$ and $26 \%$, respectively. Few children carried single infections of P. malariae (2.2\%) and P. ovale spp. (1.9\%).
\end{abstract}

Conclusion: School-age children are at significant risk from both asymptomatic and symptomatic malaria infections. Continuous systematic screening and treatment of school-age children in high-transmission settings is needed.

Keywords: Plasmodium, Malaria, School-age children, Democratic Republic Congo

*Correspondence: culleton.richard.oe@ehime-u.ac.jp

${ }^{5}$ Division of Molecular Parasitology, Proteo-Science Center, Ehime University, Ehime, Japan

Full list of author information is available at the end of the article

\section{Background}

Despite a widespread reduction in malaria-associated morbidity and mortality in the past decade, malaria remains a major public health problem in sub-Saharan Africa. In 2018, an estimated 228 million cases of malaria

(C) The Author(s) 2021. Open Access This article is licensed under a Creative Commons Attribution 4.0 International License, which permits use, sharing, adaptation, distribution and reproduction in any medium or format, as long as you give appropriate credit to the original author(s) and the source, provide a link to the Creative Commons licence, and indicate if changes were made. The images or other third party material in this article are included in the article's Creative Commons licence, unless indicated otherwise in a credit line to the material. If material is not included in the article's Creative Commons licence and your intended use is not permitted by statutory regulation or exceeds the permitted use, you will need to obtain permission directly from the copyright holder. To view a copy of this licence, visit http://creativecommons.org/licenses/by/4.0/. The Creative Commons Public Domain Dedication waiver (http://creativeco mmons.org/publicdomain/zero/1.0/) applies to the data made available in this article, unless otherwise stated in a credit line to the data. 
resulting in 405,000 deaths occurred worldwide, of which 93\% of cases and $94 \%$ of deaths occurred in Africa [1].

In sub-Saharan Africa, the vast majority of malaria cases are caused by Plasmodium falciparum, with this parasite responsible for $99.7 \%$ of all cases recorded in the region in 2018 [1]. Plasmodium malariae and Plasmodium ovale spp. are thought to be relatively uncommon [2-4] with a prevalence varying between 1 and $17 \%$ [2, 5-7]. Plasmodium malariae and Plasmodium ovale spp. frequently occur as mixed infections with other parasites, which can lead to underestimation of their true prevalence [2, 8-12].

Plasmodium malariae infection frequently results in low parasitaemia and commonly occurs in mixed infections with the more common $P$. falciparum or Plasmodium vivax $[3,13]$. Infections with $P$. malariae may remain asymptomatic for long periods, but it can cause chronic nephrotic syndrome leading to mortality [14-19].

Plasmodium ovale wallikeri and P. ovale curtisi are responsible of benign tertian malaria, rarely causing severe malaria [20]. These species may, however, cause jaundice, severe anemia, and pulmonary impairments [21], and even death if there is a delay in management $[22,23]$. The two species of $P$. ovale spp. display differences in morphology, clinical characteristics, laboratory parameters and genetics [5-7, 9, 12, 24-27].

Plasmodium vivax has occasionally been identified among populations in sub-Saharan Africa [28-31], but is considered uncommon due to the high proportion of Duffy negativity amongst the local populations of west and central Africa [32, 33].

The four species commonly found in sub-Saharan Africa, P. falciparum, P. malariae. P. ovale wallikeri and $P$. ovale curtisi share overlapping ranges and vectors. They are often found infecting the same human populations at the same time, and mixed infections in individual hosts are common. Currently, there is relatively little known about the consequences of their within-host or withinpopulation interactions, and more baseline data regarding their relative prevalence in populations with varying malaria transmission dynamics is required. Furthermore, there is a lack of data regarding the clinical outcomes of mixed species versus single species infections.

For malaria case management and control, rapid diagnostic tests (RDTs) and microscopy are the most widely used diagnostic tools that inform treatment [34]. PCR, whilst more sensitive, is relatively expensive and technically challenging, and so is rarely used as a point-of care diagnostic in endemic areas [35]. Lately, the popularity of RDTs has increased as they are cost-effective and provide an easy-to-use alternative to microscopy [36], which requires skilled microscopists to be optimally effective
$[37,38]$. However, RDTs are only sensitive and specific for parasitaemia above 200 parasites per $\mu$ l blood [39] and the most widely used are those that detect $P$. falciparum histidine-rich protein 2 (PfHRP2) [1]. The low sensitivity and specificity of both PfHRP2-based RDTs and microscopy, and a lack of experienced microscopists may result in poor malaria parasite detection $[2,40]$. Moreover, the prevalence of non-falciparum parasites may also be underestimated, especially when in co-infections with P. falciparum [2, 8-11]. PCR remains the most sensitive method for detecting non-falciparum species, even in cases of a very low parasitaemia [40].

Regarding malaria burden, in high transmission sites, symptomatic malaria occurs most often in children under five years old, whereas asymptomatic infections generally occur in older people, school-age children and adults that have acquired immunity against the disease due to repeated exposure [41-44].

School-age children are not usually covered by household-based cluster surveys and/or malaria interventions and so represent an untreated demographic that may harbour a significant parasite reservoir [45-50], thus posing a major challenge for malaria control, surveillance, and elimination strategies [45, 51-53]. Even though school-age children rarely develop complicated forms of malaria, chronic infection among this group is an important major contributor to pathology, including anaemia, and thus may have profound consequences for neuro-cognitive development and educational achievement including increased absenteeism, poor school performance, and cognitive disorders [54-59].

The Democratic Republic of Congo (DRC) is the second most malaria-affected country in the world after Nigeria, and accounts for $12 \%$ and $11 \%$ of all estimated malaria cases and deaths worldwide, respectively [1]. About $97 \%$ of its inhabitants live in perennial malaria transmission zones, in which transmission occurs for 8 to 12 months yearly [60]. In DRC, malaria is still the major cause of morbidity and mortality, accounting for more than $44 \%$ of all outpatient visits, and for $22 \%$ of deaths among children under 5 years [60]. Plasmodium falciparum is the most prevalent malaria parasite species and is responsible for most severe cases $[1,60]$. Plasmodium malariae and $P$. ovale spp. are uncommon and are mostly observed in co-infections with P. falciparum [3]. Of the two $P$. ovale species, only $P$. ovale wallikeri has been identified in the country so far [24]. Reports of the presence of $P$. vivax are rare [30,61].

Here, the burden of malaria among asymptomatic and symptomatic school-age children living in rural and urban areas of Kinshasa/DRC was assessed and the distribution of Plasmodium species in rural areas compared to urban areas was investigated in order to inform the 
design and employment of school-based control interventions for malaria in this underserved population.

\section{Methods}

\section{Study design}

A cross-sectional study was undertaken between October and November 2019 among school-age children aged 6 to 14 years in Kinshasa, DRC.

\section{Study area and study population}

The study was conducted at primary schools and health facilities in the rural area of Mont-Ngafula 2 Health Zone (HZ) and the urban area of Selembao HZ in Kinshasa city (Fig. 1). Selembao HZ is classified as an area at moderate risk while Mont-Ngafula 2 is an area at high risk of malaria [62].

In selected schools, we included all children aged 6 to 14 years with body temperatures less than $37.5^{\circ} \mathrm{C}$ during a physical examination and who did not have malariarelated symptoms (including fever, headache, fatigue, chills, nausea, vomiting) in the 2 weeks prior to the survey.

In selected health facilities, we included all outpatient children aged 6 to 14 years who exhibited fever and/ or malaria-related symptoms (headache, fatigue, chills, nausea, vomiting) within the three days prior to medical consultation and who had not taken anti-malarial drugs prior to the consultation.

\section{Sampling and sample size determination}

Both hospital-based and school-based surveys were conducted. A two-stage stratified cluster sampling protocol was performed to select two health zones (HZ) among 35 within Kinshasa and their constituent health facilities and primary schools. The sample size was determined using the standard statistical formula $n=\left(Z^{2} p(1-p) /\right.$ $\left.d^{2}\right)$ considering $95 \%$ confidence interval, $50 \%$ estimated prevalence and $5 \%$ precision. Based on this assumption, 634 school-age children (427 asymptomatic and 207 symptomatic) were included in this study.

\section{Data collection}

In schools, two visits were necessary for sample collection. The first visit consisted of the selection of primary classrooms of each primary grade followed by the distribution of written consent forms to all children belonging to the selected classroom for their parents/guardians. On the second visit, after obtaining written consent from parents/guardians, information related to gender, age, and body temperature were recorded and a physical examination carried out. An interview was conducted for asymptomatic school-age children from 4 to 6 th primary grades using a semi-structured questionnaire to record

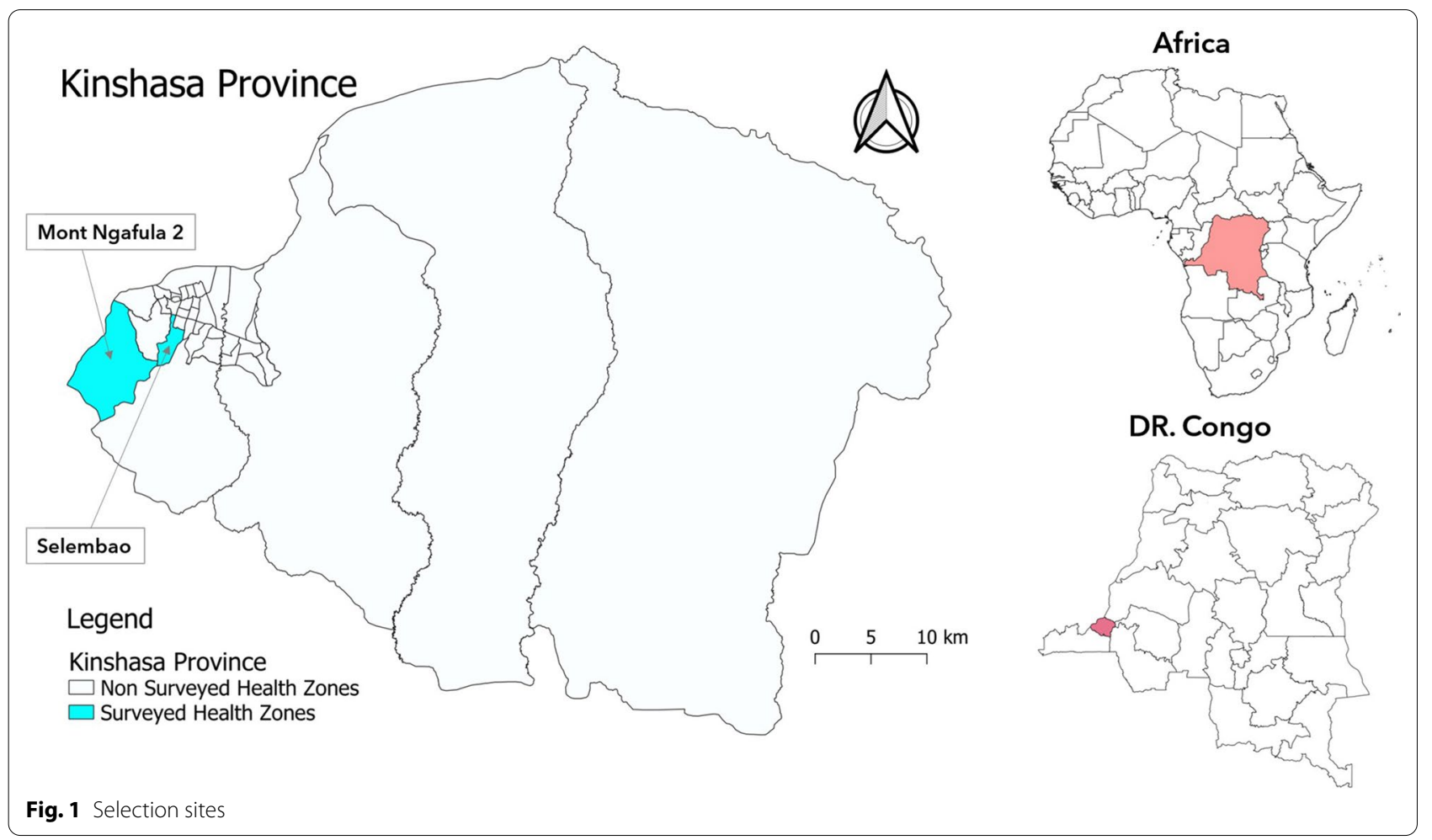


information related to the history of fever and malariarelated symptoms and treatment; socio-demographic status of parents (parent marital status, number of father's partners, father's education level, mother's education level, family size) and information related to the use of mosquito bed nets and/or indoor insecticide spray within households.

The questionnaire was written in English by the research team, and later translated into French (official language). When children were unable to give correct answers to certain questions (questions related to the education level of parent, marital status), the question(s) were addressed to parents through telephone calls.

In health facilities samples were collected day-by-day depending on health facility attendance. Malaria-related symptoms and information related to gender, age, and body temperature were recorded followed by physical examination in health facilities after obtaining consent from outpatient parents/guardians.

\section{Malaria rapid diagnostic test (RDTs)}

An experienced laboratory technician collected approximately $5 \mu$ l finger-prick blood from each child to perform RDT. The CareStart ${ }^{\mathrm{TM}}$ Malaria Pf (HRP2) Ag RDT (RMOM-02571) was used for the qualitative detection of malaria histidine-rich protein 2 in whole blood according to the manufacturer's instructions. The device remained intact for $20 \mathrm{~min}$ at room temperature, and the result was registered accordingly.

\section{Microscopy of Giemsa's solution-stained blood films}

Thick and thin blood smears were made on the same slide in schools) and health facilities. Slides made in schools were sent to the University Hospital, Kinshasa University for reading. Slides were stained for 10 min with $10 \%$ Giemsa and washed with distilled water and air-dried. Slides were read by two independent experienced laboratory technicians to determine the Plasmodium species and parasitaemia. The asexual forms were counted with reference to 200 leukocytes. In the case that fewer than 100 parasites were counted against 200 leukocytes, the count continued until 500 leukocytes were observed. Parasite density was calculated based on a total of 8000 leukocytes/ $\mu \mathrm{l}$ using the following formula: (Number of parasites counted $\times 8000$ )/Number of counted leukocytes. The parasitaemia was obtained by averaging the results of the two independents readers.

In the event of discrepant results, a third laboratory technician was involved for confirmation. The laboratory technicians counted a minimum of 100 consecutive fields in the thick blood film before classifying a slide as negative. All slides prepared in schools were read by the experienced microscopists of the Parasitology Unit of the University Hospital, Kinshasa University.

\section{DNA extraction}

In both schools and health facilities, three capillary blood drops from finger-pricks were collected and spotted onto of Whatman $903^{\mathrm{TM}}$ filter paper (Whatman plc, UK) for PCR analysis. Whatman $903^{\text {TM }}$ filter papers containing blood samples were dried and stored in individual plastic bags containing desiccant and stored at $-20{ }^{\circ} \mathrm{C}$ before transportation to Nagasaki University for PCR analysis. All DNA templates were extracted from three punched discs (6 $\mathrm{mm}$ in diameter) of blood spots using the QIAamp DNA Mini Kit using the QIAamp DNA Mini Kit ${ }^{\circledR}$ (Qiagen, USA) according to the manufacturer's instructions. DNA was eluted in $50 \mu \mathrm{L}$ of the provided buffer.

\section{Nested-PCR for malaria parasite species typing}

A nested PCR using primers targeting the Plasmodium mitochondrial cytochrome c oxidase III (cox3) gene was performed using the protocol described by Isozumi et al. [63] with minor modifications; in particular, the P. vivaxspecific primers were redesigned due to concerns regarding the non-specific binding of the originally described primers (Additional file 1: Table S1). PCR products were visualized under UV light on $1.5 \%$ agarose gels run at $100 \mathrm{~V}$ for $30 \mathrm{~min}$ and stained with Gel Red ${ }^{\circledR}$ solution for $30 \mathrm{~min}$. The outer PCR product was diluted 1:100 with sterile water and used as template for inner PCRs. Plasmodium species genotyping was performed using Plasmodium spp. outer PCR products to separately amplify specific products of $P$. falciparum, $P$. malariae, $P$. ovale spp. and $P$. vivax. PCR products were visualized under UV light on $2 \%$ agarose gels run at $100 \mathrm{~V}$ for $30 \mathrm{~min}$ and stained with Gel Red ${ }^{\circledR}$ solution for $30 \mathrm{~min}$. The outer PCR product was diluted 1:100 with sterile water and used as template for inner PCRs.

Seventy one out of 79 P. ovale spp. positive PCR products were successfully sequenced using the inner PCR forward (Nst_ovaF) primer. There was insufficient material of the remaining eight samples to make a specieslevel identification. Sequence data files were analysed using MEGA software. Sequence data from NCBI for reference [P. ovale curtisi [(GenBank: HQ712052.1) and P. ovale wallikeri (GenBank: HQ712053.1)] were used as references. From the sequence data sets, a phylogenetic tree was generated using the NJ method. According to the phylogenetic tree, the samples were assigned species designations based on clustering with the reference sequences. 


\section{Data management and analysis}

Data was double-entered and validated in EPI INFO version 3.5.1 and analysed using STATA version 14.2 (College Station. Texas, USA). Descriptive variables were analysed as proportions (qualitative variables) or by median/mean (continuous variables). Chi-square tests (or Fisher's exact tests when appropriate) and logistic regression analysis were used to assess associations between independent variables and Plasmodium spp. infection prevalence. Odds ratios (ORs) and 95\% confidence intervals (CIs) were derived. Significance was set at $p<0.05$.

\section{Ethical considerations}

The study was approved by the Ethics committees of the School of Public Health, Kinshasa University, DRC (Approval number: ESP/CE/042/2019) and the Institute of Tropical Medicine, Nagasaki University (Approval number: 190110208-2). Written informed consent was obtained from children's parents/guardians and assent from children $\geq 7$ years old were sought. The written informed consent document was provided either in French (official language) or Lingala (local language) depending on the parent's educational background. All malaria positive cases with RDTs were treated according to national malaria diagnosis and treatment guidelines.

\section{Results}

\section{Description of study population}

A total of 634 (210 asymptomatic and 105 symptomatic in the rural area; 217 asymptomatic and 102 symptomatic in the urban area) children aged 6 to 14 years old were included in this study.

Their median (interquartile range) age was 9 (7-11) [asymptomatic: 9 (7-11); symptomatic: 8 (7-9)] in the rural area, and 9 (7-10) [asymptomatic: 8 (7-10); symptomatic: $9(7-12)$ ] in the urban area. Children aged 6 to 9 years accounted for $59.7 \%(188 / 315)$ [asymptomatic: $50.5 \%(106 / 210)$; symptomatic: $78.1 \%(82 / 105)]$ in the rural area, and $63.3 \%(202 / 319)$ [asymptomatic: $68.2 \%$ (148/217); symptomatic: $52.9 \%(54 / 102)]$ in the urban setting; 49.5\% (156/315) [asymptomatic: 49.5\% (104/210); symptomatic: $49.5 \%(52 / 105)]$ in the rural area, and $51.4 \%$ (164/319) [asymptomatic: $54.8 \%$ (119/217); symptomatic: $41.1 \%(45 / 102)]$ in the urban setting were females (Additional file 1: Table S2).

\section{Information relating to sociodemographic characteristics of asymptomatic school-age children and malaria preventive measures}

Among 227 (131 in the rural area and 96 in the urban area) asymptomatic school-age children who were interviewed, most of children $(\geq 80 \%)$ lived together with their parents in both rural and urban areas, 60\% had at least one mosquito bed net and $31 \%$ slept under a mosquito net the night before the interview in the rural area whereas $28 \%$ had at least one mosquito bed net and $25 \%$ slept under a mosquito net the night before in the urban area (Additional file 1: Table S3).

\section{History of last fever and/or malaria-like symptoms}

Among 131 children interviewed in the rural area, 54\% reported a malaria episode in the three months prior to the survey. Only $34 \%$ went to a health facility, and the majority of these $(82 \%)$ went to a health centre. Fortyfour percent of children reported having self-medicated (of which 33\% had used sulfadoxine/pyrimethamine (SP) and $11 \%$ artemisinin-based combination therapy) given by their parents without a confirmed malaria diagnosis. Fifty-two percent of children missed classes and among these, 39\% missed five days or more (Fig. 2).

Among 96 children interviewed in the urban area, a $78 \%$ reported a malaria episode in the three months prior to the survey. Only $39 \%$ went to a health facility, and the majority of these (95\%) went to a health centre. Seventeen percent of children reported having self-medicated with anti-malarial drugs (of which 25\% used SP, 25\% used artemisinin-based combination therapy and 50\% did not remember the drug's name) given by their parents without a confirmed malaria diagnosis. Forty-four percent of children missed classes and among these, 38\% missed five days or more (Fig. 2).

Symptoms of outpatient school-age children at admission All 207 children (105 in the rural area and 102 in the urban area) attending health facilities had fever symptoms $(100 \%)$, followed by vomiting (37\%), fatigue (28\%) and diarrhoea (23\%) in the rural area versus headache (72\%), fatigue (50\%), lack of appetite (49\%) and abdominal pain $(48 \%)$ in the urban setting as major symptoms (Additional file 1: Table S4).

\section{Prevalence of Plasmodium spp. infections by microscopy, RDT and PCR}

The overall prevalence of Plasmodium spp. was 33\%, 42\% and $62 \%$ among asymptomatic children and 59\%, 64\% and $94 \%$ in symptomatic children by microscopy, RDT and PCR, respectively (Table 1 ).

\section{Comparison of Plasmodium infection prevalence between rural and urban areas among asymptomatic and symptomatic school-age children by PCR}

All malaria parasite species were significantly more prevalent in the rural area compared to the urban setting in asymptomatic infections $(\mathrm{p}<0.001)$, whereas in symptomatic infections, $P$. malariae was significantly less 


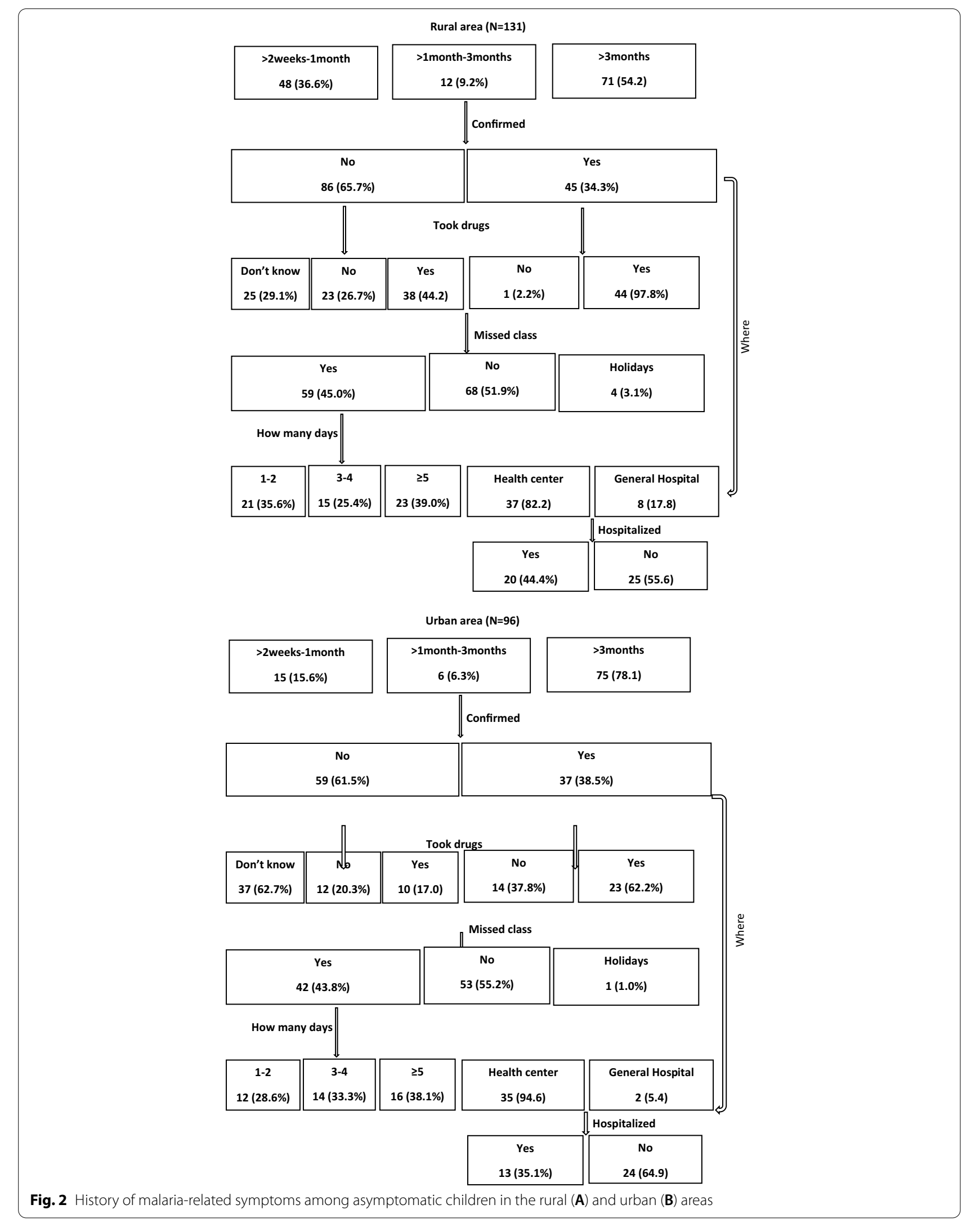


Table 1 Prevalence of Plasmodium spp. infections by microscopy, RDTs and PCR in asymptomatic and symptomatic infections

\begin{tabular}{lll}
\hline Technique & $\begin{array}{l}\text { Asymptomatic infection } \\
(\mathbf{N}=\mathbf{4 2 7})\end{array}$ & $\begin{array}{l}\text { Symptomatic } \\
\text { infection } \\
\mathbf{( N = 2 0 7 )} \\
\mathbf{n}(\%)\end{array}$ \\
\hline Microscopy & $\mathbf{n}(\%)$ & $123(59.4)$ \\
RDT & $140(32.8)$ & $133(64.3)$ \\
PCR & $177(41.5)$ & $196(94.7)$ \\
\hline
\end{tabular}

prevalent in the rural area compared to the urban setting (7.6 versus $17.7 \%, \mathrm{p}=0.03$ ). No $P$. vivax infections were observed (Table 2).

Out of 71 children infected with $P$. ovale spp., 53 (75\%), 17 (24\%) and 1 (1\%) harboured P. ovale curtisi, P. ovale wallikeri and mixed $P$. ovale curtisi $+P$. ovale wallikeri infections, respectively. Plasmodium ovale curtisi was more frequent than $P$. ovale wallikeri in the rural area ( 86.0 vs $14.0 \%)$ while they were equally distributed in urban area (48\% vs $48 \%$ ) with one child (5\%) harbouring a mixed $P$. ovale curtisi $+P$. ovale wallikeri infection (Table 3).

\section{Plasmodium species composition}

Of the 462 malaria positive children, 270 (168 asymptomatic and 102 symptomatic) resided in the rural area and 192 (98 asymptomatic and 94 symptomatic) in the urban setting.

In the rural area, 261 (97\%) [161 (96\%) asymptomatic and 100 (98\%) symptomatic] carried P. falciparum, 73 (27\%) [66 (39\%) asymptomatic and 7 (7\%) symptomatic] carried P. malariae, and 54 (20\%) [35 (21\%) asymptomatic
Table 3 Distribution of $P$. ovale curtisi and P. ovale wallikeri by location, health status, age and gender $(N=71)$

\begin{tabular}{|c|c|c|c|}
\hline & $\begin{array}{l}\text { Poc }(\mathrm{N}=53) \\
\mathrm{n}(\%)\end{array}$ & $\begin{array}{l}\text { Pow }(N=17) \\
n(\%)\end{array}$ & $\begin{array}{l}\text { Poc }+ \text { Pow }(\mathrm{N}=1) \\
\mathrm{n}(\%)\end{array}$ \\
\hline \multicolumn{4}{|l|}{ Location } \\
\hline Rural & $43(86.0)$ & $7(14.0)$ & $0(0.0)$ \\
\hline Urban & $10(47.6)$ & $10(47.6)$ & $1(4.8)$ \\
\hline \multicolumn{4}{|l|}{ Health status } \\
\hline Asymptomatic & $33(76.7)$ & $10(23.3)$ & $0(0.0)$ \\
\hline Symptomatic & $20(71.4)$ & $7(25.0)$ & $1(3.4)$ \\
\hline \multicolumn{4}{|l|}{ Age (years) } \\
\hline $6-9$ & $28(70.0)$ & $11(27.5)$ & $1(2.5)$ \\
\hline $10-14$ & $25(80.7)$ & $6(19.3)$ & $0(0.0)$ \\
\hline \multicolumn{4}{|l|}{ Gender } \\
\hline Female & $22(73.3)$ & $7(23.3)$ & $1(3.3)$ \\
\hline Male & 31 (75.6) & $10(24.4)$ & $0(0.0)$ \\
\hline
\end{tabular}

Poc, P. ovale curtisi; Pow, P. ovale wallikeri

and 19 (19\%) symptomatic) carried $P$. ovale spp. parasites (Table 4, Additional file 2: Figure S1K \& L).

In the urban area, 179 (93\%) [87 (89\%) asymptomatic and 92 (98\%) symptomatic] carried P. falciparum, 37 (19\%) [19 (19\%) asymptomatic and 18 (19\%) symptomatic] carried P. malariae, and 25 (13.0\%) [11 (11.2\%) asymptomatic and 14 (18\%) symptomatic] carried $P$. ovale spp. parasites (Table 4, Additional file 2: Figure S1I \& J).

There were 89 (53\%), $3(1.8 \%)$ and $4(2.4 \%)$ single infections of $P$. falciparum, $P$. malariae and $P$. ovale spp., in asymptomatic participants in the rural area (Table 4, Additional file 2: Figure S1K), while there were $79(77 \%), 0$ and 1 (1\%) in symptomatic participants, respectively (Table 4, Additional file 2: Figure S1L). There were $73(75 \%), 5(5 \%)$ and $4(4 \%)$ single

Table 2 Comparison of Plasmodium infection prevalence between rural and urban areas among asymptomatic and symptomatic school-age children

\begin{tabular}{|c|c|c|c|c|c|c|c|c|c|c|}
\hline \multirow[t]{3}{*}{ Malaria infections } & \multicolumn{4}{|c|}{ Asymptomatic infection } & \multirow[t]{3}{*}{$p$-value } & \multicolumn{4}{|c|}{ Symptomatic infection } & \multirow[t]{3}{*}{ p-value } \\
\hline & \multicolumn{2}{|c|}{ Rural area $(N=210)$} & \multicolumn{2}{|c|}{ Urban area $(\mathrm{N}=217)$} & & \multicolumn{2}{|c|}{ Rural area $(\mathrm{N}=105)$} & \multicolumn{2}{|c|}{ Urban area $(\mathrm{N}=102)$} & \\
\hline & Number & $\%$ & Number & $\%$ & & Number & $\%$ & Number & $\%$ & \\
\hline \multicolumn{11}{|l|}{ Plasmodium species } \\
\hline Plasmodium spp. & 168 & 80.0 & 98 & 45.2 & $<0.001$ & 102 & 97.1 & 94 & 92.2 & 0.11 \\
\hline P. falciparum & 161 & 76.7 & 87 & 40.0 & $<0.001$ & 101 & 96.2 & 92 & 90.2 & 0.09 \\
\hline P. malariae $e^{\mathrm{a}}$ & 66 & 31.4 & 19 & 8.8 & $<0.001$ & 8 & 7.6 & 18 & 17.7 & 0.03 \\
\hline P. avale spp. & 35 & 16.7 & 11 & 5.1 & $<0.001$ & 19 & 18.1 & 14 & 13.7 & 0.39 \\
\hline \multicolumn{11}{|c|}{ Type of Plasmodium infection } \\
\hline Single infection & 96 & 45.7 & 82 & 37.8 & $<0.001$ & 80 & 76.2 & 70 & 68.3 & 0.10 \\
\hline Mixed infection & 72 & 34.3 & 16 & 7.4 & $<0.001$ & 22 & 21 & 24 & 23.5 & 0.22 \\
\hline
\end{tabular}

${ }^{\text {a }}$ Two cases of $P$. malariae by microscopy 
Table 4 Proportion of Plasmodium species in asymptomatic and symptomatic school-age children by location

\begin{tabular}{|c|c|c|c|c|c|c|c|c|}
\hline & \multicolumn{4}{|c|}{ Rural area $(N=270)$} & \multicolumn{4}{|c|}{ Urban area $(\mathrm{N}=192)$} \\
\hline & \multicolumn{2}{|c|}{$\begin{array}{l}\text { Asymptomatic } \\
(\mathrm{N}=168)\end{array}$} & \multicolumn{2}{|c|}{ Symptomatic $(N=102)$} & \multicolumn{2}{|c|}{ Asymptomatic $(\mathrm{N}=98)$} & \multicolumn{2}{|c|}{$\begin{array}{l}\text { Symptomatic } \\
(\mathrm{N}=94)\end{array}$} \\
\hline \multicolumn{9}{|l|}{ Type of Plasmodium infection } \\
\hline Single infection & 96 & 57.1 & 80 & 78.4 & 82 & 83.7 & 70 & 74.5 \\
\hline Mixed infection & 72 & 42.9 & 22 & 21.6 & 16 & 16.3 & 24 & 25.5 \\
\hline \multicolumn{9}{|l|}{ Plasmodium species composition } \\
\hline P. falciparum & 89 & 53.0 & 79 & 77.4 & 73 & 74.5 & 68 & 72.3 \\
\hline P. malariae & 3 & 1.8 & 0 & 0.0 & 5 & 5.1 & 2 & 2.1 \\
\hline P. ovale spp. & 4 & 2.4 & 1 & 1.0 & 4 & 4.1 & 0 & 0.0 \\
\hline P. falciparum + P. malariae & 41 & 24.4 & 3 & 3.9 & 9 & 9.2 & 10 & 10.6 \\
\hline P. falciparum + P. ovale spp. & 9 & 5.4 & 14 & 13.7 & 2 & 2.0 & 8 & 8.5 \\
\hline P. malariae + P.ovale spp. & 0 & 0.0 & 0 & 0.0 & 2 & 2.0 & 0 & 0.0 \\
\hline P. falciparum + P.malariae + P. ovale spp. & 22 & 13.1 & 4 & 3.9 & 3 & 3.1 & 6 & 6.4 \\
\hline
\end{tabular}

infections of P. falciparum, P. malariae and P. ovale, in asymptomatic participants in the urban area (Table 4 , Additional file 2: Figure S1K), while there were 68 (72\%), $2(2 \%)$ and 0 in symptomatic participants, respectively (Table 4, Additional file 2: Figure S1J).

There were significantly more infections involving $P$. malariae and $P$. ovale spp. in asymptomatic children compared to symptomatic children in the rural area (Table 4, Additional file 2: Figure S1G \& H), whereas there were similar rates of carriage of these species in asymptomatic and symptomatic infections in the urban setting (Table 4, Additional file 2: Figure S1E \& F).

In the rural area, 94 (35\%) [72 (43\%) asymptomatic and $22(22 \%)$ symptomatic] (Table 4, Additional file 2: Figure S1C \& D), individuals carried mixed infections, whereas in the urban area $40(20 \%)$ [16 (16\%) asymptomatic and 24 (26\%) symptomatic] carried mixed infections (Table 4, Additional file 2: Figure S1A \& B). In the rural setting there was a large difference in the proportion of single and mixed species infections between asymptomatic and symptomatic children, with more mixed species infections observed in asymptomatic children compared to symptomatic children (Additional file 2: Figure S1C \& D). However, in the urban region there was little difference in the proportion of single and mixed species infections between asymptomatic and symptomatic children (Additional file 2: Figure $\mathrm{S} 1 \mathrm{~A} \& \mathrm{~B})$.

Of $12 P$. malariae and $11 P$. ovale spp. single infections identified by PCR, six were positive by PfHRP2based RDT; one child harboured $P$. malariae and five children carried $P$. ovale spp. infections.

\section{Association age/gender with Plasmodium species infections}

Regarding the distribution of the malaria parasite species infecting asymptomatic children by age in the rural and urban areas, the trend of $P$. falciparum did not change with age in the rural setting, while it increased with age in the urban area. Plasmodium malariae and P. ovale spp. infections were more common in children aged 10 years and above in the rural area (Fig. 3).

In the rural area, asymptomatic children aged 10 to 14 years were significantly more likely to be infected with $P$. malariae $(38.5$ versus $24.5 \%, \mathrm{p}=0.03$ ) and $P$. ovale spp. (23.1 versus $10.4 \%, \mathrm{p}=0.014$ ) than those aged 6 to 9 years. In the urban area, however, older children were more likely to carry $P$. falciparum than younger children (50.7 versus 35.1\%, $\mathrm{p}=0.029$ ) (Additional file 1: Table S5a). Older children were less likely to harbour single species (33.7 versus $57.6 \%$ ) and more likely to harbour mixed species infections ( 44.2 versus $24.5 \%),(\mathrm{p}=0.02)$ infections in the rural area, whereas in the urban area older children were similarly likely to harbour single species (46.4 versus 33.8\%) and mixed species infections (8.7 versus 6.8\%), $(\mathrm{p}=0.13)$ (Additional file 1: Table S6a).

There was no association between gender and any particular Plasmodium species infection in either the rural or urban areas (Additional file 1: Table S5a).

In symptomatic children, there was no association between age or gender with particular malaria parasite infections in either the rural or the urban areas except for P. ovale spp. which infected younger children more often in the urban setting (4.2 versus $22.2 \%, \mathrm{p}=0.009$ ) (Additional file 1: Table S5b). Age and gender were not associated with carriage of single compared to mixed infections 

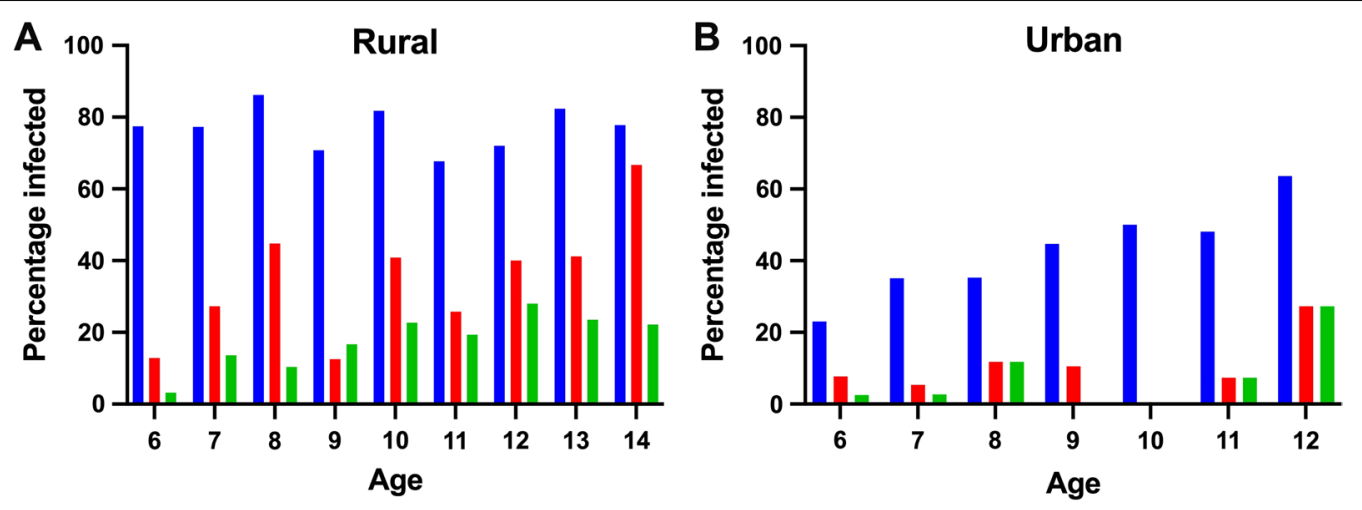

P. falciparum $\square$ P. malariae $\square$ P. ovalespp.

Fig. 3 Species composition of Plasmodium infections stratified by age in asymptomatic school-age children living in rural $(\mathbf{A} n=210)$ and urban areas $(\mathbf{B} n=214)$. The number of children aged 13 and 14 years was very low in the urban area and excluded from the figure

in either the rural or the urban areas (Additional file 1: Table S6b).

\section{Predictors of asymptomatic malaria infection}

Residence in the rural setting was associated with an increased risk of asymptomatic malaria parasite carriage. There was an approximately five times greater risk of asymptomatic carriage of malaria parasites for children living in the rural, as opposed to urban area $(\mathrm{p}<0.001)$. Other investigated factors were not associated with increased risk of asymptomatic malaria infection (Additional file 1: Table S7).

\section{Discussion}

This study aimed to measure the burden of Plasmodium spp. infections including P. falciparum and non-falciparum single and mixed infections amongst asymptomatic and symptomatic school-age children living in rural and urban areas in Kinshasa, DRC.

Kinshasa, the capital city of DRC, constitutes an urban malaria facies, where malaria prevalence is moderate, with an average of $12 \%$ of the population infected at any given time in the city, with increase prevalence variations away from the city centre [60, 64]. Malaria transmission rates are not homogenous throughout the city and depend on the population density and level of urbanization. The prevalence is highest in the more densely populated and less urbanized zones in the periphery [60, 62].

Additionally, malaria infection usually follows a seasonal pattern regulated by mosquito population fluctuations controlled by climate $[62,65]$. This study was conducted at the beginning of the rainy season between October and November when conditions of temperature and humidity are favourable for malaria transmission.
Temperature, humidity, and rainfall constitute important drivers of mosquito dynamics and malaria risk [65-67].

The overall prevalence of Plasmodium spp. was 32\%, $41 \%$ and $62 \%$ among asymptomatic children and 59\%, $64 \%$ and $95 \%$ in symptomatic children by microscopy, RDT and PCR, respectively. The high prevalence found in both asymptomatic and symptomatic children highlights the importance of malaria in this underserved population in Kinshasa.

In asymptomatic children, all Plasmodium species infections were significantly more prevalent in the rural area compared to the urban setting. There was a significant difference in malaria prevalence in children living in the rural area as opposed to the urban setting, with the former significantly more likely to be infected with malaria parasites. This finding is in agreement with numerous previous reports, and likely reflects the fact that the ratio of mosquitoes to humans is higher in rural areas than in urban areas $[62,65]$.

We found that age, generally, was not associated with Plasmodium spp. infections. However, there was a significant association between age and asymptomatic $P$. malariae and $P$. ovale spp. infections in the rural area, and $P$. falciparum infections in the urban setting, with children aged 10 to 14 years more infected than those aged 6 to 9 years. Older children were also the group most likely to harbour more single and mixed infections than younger ones. The proportion of children infected with $P$. falciparum remained constant for all ages in the rural area, while it increased with age in the urban setting. Plasmodium malariae and P. ovale spp. infections increased with age in the rural area while they did not do so in the urban setting. That difference may be due to age-related acquisition of parasite-tolerating immunity [68-70]. It has been shown that in malaria tropical facies, 
malaria pre-immunity starts building up around 10 years [71]. It may also reflect the relative force of infection of the species, with that of $P$. falciparum being higher than the other two species in the rural setting.

We found a low prevalence of single infections of $P$. malariae and $P$. ovale spp., and a high prevalence of single infection of $P$. falciparum and mixed species infections in both rural and urban areas in agreement with previous reports from Africa [2, 6, 8-12].

Among children infected with $P$. ovale spp., we found $75 \%, 24 \%$ and $1 \%$ children harboured P.ovale curtisi, $P$. ovale wallikeri and mixed P.ovale curtisi $+P$. ovale wallikeri. This finding highlights the fact that $P$. ovale curtisi appears to be more prevalent than P. ovale wallikeri [72]. This is the first report of $P$. ovale curtisi in DRC; prior to this study only $P$. ovale wallikeri has been reported [24]. Additionally, this study confirms that $P$. ovale curtisi and $P$. ovale wallikeri can be found in co-infections of the same host $[6,9,73]$.

There is a need, perhaps, to focus more attention on the non-falciparum malaria parasites of Africa. The ability of $P$. ovale curtisi and P. ovale wallikeri to produce hypnozoites, and the quartan intra-erythrocytic cycle time of $P$. malariae may provide these species with a mechanism for evading the current artemisinin-based combination therapy for uncomplicated malaria $[9,74]$.

The presence of $P$. ovale spp. and $P$. malariae, coinfected with $P$. falciparum, highlights the impact of those two parasites in asymptomatic and chronic malaria infection. Plasmodium malariae and P. ovale spp. are not usually associated with severe malaria, but $P$. malariae may be responsible for chronic nephrotic syndrome [14$17,75,76]$, which can be fatal [14-16, 75], and chronic infections that can last for years $[15,76]$, even after leaving endemic regions $[15,76]$. Plasmodium ovale spp. is responsible for relapses after months or even years without symptoms due to the presence of hypnozoites [7783 ] and it has been shown to cause severe disease and even death on occasion [21-23, 84, 85].

Our data are in agreement with previous reports that show that $P$. malariae is much less likely to be observed in mixed species infections with $P$. falciparum in symptomatic malaria infections when the transmission rate of malaria is high $[86,87]$. The reason for this is currently unclear. It is possible that there is a protective effect of mixed infection with $P$. malariae on the severity of the disease caused by $P$. falciparum, perhaps mediated through cross-immunity. It is also possible that in symptomatic $P$. falciparum infections, this species competitively excludes co-infecting species due to increased parasitaemia. This exclusion could result from withinhost competition for resources [88], or through hostimmune mediated mechanisms in which the innate immune response triggered by the high parasitaemia $P$. falciparum disproportionately affects the less dominant of the species in the co-infection. A further possibility is that the nested PCR methodology used here to determine parasite species may miss the less common of co-infecting species when the disparity between them is large as is likely in symptomatic $P$. falciparum infected patients.

\section{Conclusion}

There is a need to include school-age children in malaria control, surveillance, and elimination strategies. Therefore, a continuous systematic school-based prevention, screening, and treatment of children in high-transmission settings may strengthen malaria intervention measures.

\section{Supplementary Information}

The online version contains supplementary material available at https://doi. org/10.1186/s12936-021-03919-4.

Additional file 1: Table S1. Primer sequences and PCR conditions for Plasmodium spp. and Plasmodium genotyping amplification. Table S2. Description of study population. Table S3. Sociodemographic characteristics of asymptomatic school-age children and malaria preventive measures $(\mathrm{N}=227)$. Table S4. Symptoms of outpatient school-age children at admission ( $\mathrm{N}=207)$. Table S5a. Association between age and gender with asymptomatic malaria infection in rural and urban areas. Table S5b. Association between age and gender with symptomatic malaria infection in rural and urban areas. Table S6a. Association between age / gender with asymptomatic malaria single and mixed infection in rural and urban areas. Table S6b. Association between age / gender with symptomatic malaria single and mixed infections in rural and urban areas. Table S7. Predictors of asymptomatic malaria infection (bivariate analysis vs multivariate analysis). Note: COR: Crude odds ratio; $\mathrm{Cl}$ : Confidence interval; $\mathrm{AOR}$ : Adjusted odds ratio

Additional file 2: Figure S1. Species composition of Plasmodium infections in 98 asymptomatic (Panels A, E and I) and 94 symptomatic (B, F, and J) children in the urban Selembao health zone (HZ), and 168 asymptomatic (Panels C, G and K) and 102 symptomatic (Panels D, H, and L) children in the rural Mont-Ngafula $2 \mathrm{HZ}$. The urban Selembao HZ: Single and mixed infections in asymptomatic (A) and symptomatic (B) children. Malaria parasite species composition in asymptomatic (E \& I) and symptomatic ( $F$ \& J) children. The rural Mont-Ngafula $2 \mathrm{HZ}$ : Single and mixed infections in asymptomatic (C) and symptomatic (D) children. Malaria parasite species composition in asymptomatic $(G \& K)$ and symptomatic $(\mathrm{H} \& \mathrm{~L}) . \mathrm{Pf}=$ Plasmodium falciparum, $\mathrm{Pm}=$ Plasmodium malariae, $\mathrm{Po}=\mathrm{P}$. ovale wallikeri and P. ovale curtisi ("P. ovale" includes both P. ovale species").

\section{Acknowledgements}

We thank the authorities of the Kinshasa Provincial Health Inspectorate and Institut National de Recherche Biomédicale (INRB) for facilitation. Special thanks and gratitude to Dr. Mamie Lau, the Head of Selembao Health Zone; Dr. Edo Molamba the Head of Mongafula- 2 Health Zone as well as the Directors of the primary schools Ecole chretienne Edmond and Cité des aveugles for supervision. We also thank Dr. Akintije Simba Calliope for contributing to the discussion of this study.

\section{Authors' contributions}

Conceptualization: SSN, TY, RC. Data curation: SSN, RC. Formal analysis: SSN, RC. Investigation: SSN, TY, HA. Methodology: SSN, RC, TY, TM. Contributed materials: RC. Supervision: RC, TY, TM, SA, JJM. Writing-original draft: SSN. Writing review \& editing: SSN, RC, TY, TM, SVS, HA, SA. Laboratory works: SSN, SVS, $H A, R C$. All authors read and approved the final manuscript. 


\section{Funding}

This work was supported by the Japan International Cooperation Agency and the Joint Usage/Research Center on Tropical Disease, Institute of Tropical Medicine, Nagasaki University (2020-Ippan-14, 2020-Ippan-23).

\section{Availability of data and materials}

The datasets used and/or analysed during the current study are available from the first author (SSN) upon request.

\section{Declarations}

\section{Ethics approval and consent to participate}

The study was approved by the ethics committees of the School of Public Health, Kinshasa University, DRC (Approval number: ESP/CE/042/2019) and the Institute of Tropical Medicine, Nagasaki University (Approval number: 190110208-2). Written informed consent was obtained from children's parents/guardians and assent from children $\geq 7$ years old were sought. The written informed consent document was provided either in French (official language) or Lingala (local language) depending on the parent's educational background. All malaria positive cases from RDTs were treated according to national malaria diagnosis and treatment guidelines.

\section{Consent for publication}

Consent for publication was obtained from the parents/guardians of each child during the study.

\section{Competing interests}

The authors declare that they have no competing interests.

\section{Author details}

${ }^{1}$ Department of International Health and Medical Anthropology, Institute of Tropical Medicine, Nagasaki University, Nagasaki, Japan. ${ }^{2}$ Graduate School of Biomedical Sciences, Nagasaki University, Nagasaki, Japan. ${ }^{3}$ Program for Nurturing Global Leaders in Tropical and Emerging Communicable Diseases, Nagasaki University, Nagasaki, Japan. ${ }^{4}$ Institut National de Recherche Biomédicale, Kinshasa, Democratic Republic of Congo. ${ }^{5}$ Division of Molecular Parasitology, Proteo-Science Center, Ehime University, Ehime, Japan. ${ }^{6}$ Department of Tropical Medicine and Parasitology, Faculty of Medicine, Juntendo University, Tokyo, Japan.

\section{Accepted: 16 September 2021}

Published online: 02 October 2021

\section{References}

1. WHO. World malaria report 2019. Geneva: World Health Organization; 2019. https://www.who.int/publications/i/item/9789241565721. Accessed 2 Feb 2020.

2. Doctor SM, Liu Y, Anderson OG, Whitesell AN, Mwandagalirwa MK, Muwonga J, et al. Low prevalence of Plasmodium malariae and Plasmodium ovale mono-infections among children in the Democratic Republic of the Congo: a population-based, cross-sectional study. Malar J. 2016;15:350.

3. Collins WE, Jeffery GM. Plasmodium malariae: parasite and disease. Clin Microbiol Rev. 2007;20:579-92.

4. Sutherland CJ, Tanomsing N, Nolder D, Oguike M, Jennison C, Pukrittayakamee $\mathrm{S}$, et al. Two nonrecombining sympatric forms of the human malaria parasite Plasmodium ovale occur globally. J Infect Dis. 2010;201:1544-50.

5. Bruce MC, Macheso A, Kelly-Hope LA, Nkhoma S, McConnachie A, Molyneux ME. Effect of transmission setting and mixed species infections on clinical measures of malaria in Malawi. PLoS ONE. 2008;3:e2775.

6. Fançony C, Gamboa D, Sebastião Y, Hallett R, Sutherland C, Sousa-Figueiredo JC, et al. Various pfcrt and pfmdr1 genotypes of Plasmodium falciparum cocirculate with $P$. malariae, $P$. ovale spp., and $P$. vivax in northern Angola. Antimicrob Agents Chemother. 2012;56:5271-7.

7. Oguike MC, Betson M, Burke M, Nolder D, Stothard JR, Kleinschmidt I, et al. Plasmodium ovale curtisi and Plasmodium ovale wallikeri circulate simultaneously in African communities. Int J Parasitol. 2011;41:677-83.
8. Asua V, Tukwasibwe S, Conrad M, Walakira A, Nankabirwa Jl, Mugenyi L, et al. Plasmodium species infecting children presenting with malaria in Uganda. Am J Trop Med Hyg. 2017;97:753-7.

9. Dinko B, Oguike MC, Larbi JA, Bousema T, Sutherland CJ. Persistent detection of Plasmodium falciparum, P. malariae, P. ovale curtisi and P. ovale wallikeri after ACT treatment of asymptomatic Ghanaian school-children. Int J Parasitol Drugs Drug Resist. 2013;3:45-50.

10. Dormond L, Jaton-Ogay K, de Vallière S, Genton B, Bille J, Greub G. Multiplex real-time PCR for the diagnosis of malaria: correlation with microscopy. CMI. 2011;17:469-75.

11. Kasehagen LJ, Mueller I, McNamara DT, Bockarie MJ, Kiniboro B, Rare L, et al. Changing patterns of Plasmodium blood-stage infections in the Wosera region of Papua New Guinea monitored by light microscopy and high throughput PCR diagnosis. Am J Trop Med Hyg. 2006;75:588-96.

12. Lalremruata A, Jeyaraj S, Engleitner T, Joanny F, Lang A, Bélard S, et al. Species and genotype diversity of Plasmodium in malaria patients from Gabon analysed by next generation sequencing. Malar J. 2017;16:398.

13. Brouwer EE, van Hellemond JJ, van Genderen PJJ, Slot E, van Lieshout $L$, Visser LG, et al. A case report of transfusion-transmitted Plasmodium malariae from an asymptomatic non-immune traveller. Malar J. 2013;12:439.

14. Eiam-Ong S. Malarial nephropathy. Semin Nephrol. 2003;23:21-33.

15. Hedelius R, Fletcher JJ, Glass WF 2nd, Susanti Al, Maguire JD. Nephrotic syndrome and unrecognized Plasmodium malariae infection in a US Navy sailor 14 years after departing Nigeria. J Travel Med. 2011;18:288-91.

16. Hwang J, Cullen KA, Kachur SP, Arguin PM, Baird JK. Severe morbidity and mortality risk from malaria in the United States, 1985-2011. Open Forum Infect Dis. 2014;1:ofu034.

17. Langford S, Douglas NM, Lampah DA, Simpson JA, Kenangalem E, Sugiarto $P$, et al. Plasmodium malariae infection associated with a high burden of anemia: a hospital-based surveillance study. PLoS Negl Trop Dis. 2015;9:e0004195.

18. Roman DNR, Rosalie NNA, Kumar A, Luther KMM, Singh V, Albert MS. Asymptomatic Plasmodium malariae infections in children from suburban areas of Yaoundé, Cameroon. Parasitol Int. 2018;67:29-33.

19. Scuracchio P, Vieira SD, Dourado DA, Bueno LM, Colella R, Ramos-Sanchez EM, et al. Transfusion-transmitted malaria: case report of asymptomatic donor harboring Plasmodium malariae. Rev Inst Med Trop Sao Paulo. 2011;53:55-9.

20. Collins WE, Jeffery GM. Plasmodium ovale: parasite and disease. Clin Microbiol Rev. 2005;18(3):570-81.

21. Lau YL, Lee WC, Tan LH, Kamarulzaman A, Syed Omar SF, Fong MY, et al. Acute respiratory distress syndrome and acute renal failure from Plasmodium ovale infection with fatal outcome. Malar J. 2013;12:389.

22. Alemu A, Fuehrer HP, Getnet G, Tessema B, Noedl H. Plasmodium ovale curtisi and Plasmodium ovale wallikeri in North-West Ethiopia. Malar J. 2013; $12: 346$.

23. Groger M, Veletzky L, Lalremruata A, Cattaneo C, Mischlinger J, Manego Zoleko R, et al. Prospective clinical and molecular evaluation of potential Plasmodium ovale curtisi and wallikeri relapses in a high-transmission setting. Clin Infect Dis. 2019;69:2119-26.

24. Gabrielli S, Bellina L, Milardi GL, Katende BK, Totino V, Fullin V, et al. Malaria in children of Tshimbulu (Western Kasai, Democratic Republic of the Congo): epidemiological data and accuracy of diagnostic assays applied in a limited resource setting. Malar J. 2016;15:81.

25. Haiyambo DH, Uusiku P, Mumbengegwi D, Pernica JM, Bock R, Malleret $B$, et al. Molecular detection of $P$. vivax and $P$. ovale foci of infection in asymptomatic and symptomatic children in Northern Namibia. PLoS Negl Trop Dis. 2019;13:e0007290.

26. Miller RH, Obuya CO, Wanja EW, Ogutu B, Waitumbi J, Luckhart S, et al. Characterization of Plasmodium ovale curtisi and $P$. ovale wallikeri in Western Kenya utilizing a novel species-specific real-time PCR assay. PLoS Negl Trop Dis. 2015;9:e0003469.

27. Woldearegai TG, Lalremruata A, Nguyen TT, Gmeiner M, Veletzky L, Tazemda-Kuitsouc GB, et al. Characterization of Plasmodium infections among inhabitants of rural areas in Gabon. Sci Rep. 2019;9:9784.

28. Culleton R, Ndounga M, Zeyrek FY, Coban C, Casimiro PN, Takeo S, et al. Evidence for the transmission of Plasmodium vivax in the Republic of the Congo, West Central Africa. J Infect Dis. 2009;200:1465-9. 
29. Fru-Cho J, Bumah WV, Safeukui I, Nkuo-Akenji T, Titanji VPK, Haldar K. Molecular typing reveals substantial Plasmodium vivax infection in asymptomatic adults in a rural area of Cameroon. Malar J. 2014;13:170.

30. Kavunga-Membo H, llombe G, Masumu J, Matangila J, Imponge J, Manzambi E, et al. Molecular identification of Plasmodium species in symptomatic children of Democratic Republic of Congo. Malar J. 2018;17:334.

31. Ménard D, Barnadas C, Bouchier C, Henry-Halldin C, Gray LR, Ratsimbasoa $A$, et al. Plasmodium vivax clinical malaria is commonly observed in Duffynegative Malagasy people. Proc Natl Acad Sci USA. 2010;107:5967-71.

32. Boyd MF, Stratman-Thomas WK. Studies on benign tertian malaria: 4. On the refractoriness of negroes to inoculation with Plasmodium vivax. Am J Epidemiol. 1933;18:485-9.

33. O'Leary PA. Treatment of neurosyphilis by malaria: report on the three years' observation of the first one hundred patients Treated. JAMA. 1927:89:95-100.

34. WHO. Guidelines for the treatment of malaria. Geneva: World Health Organization; 2010.

35. Kamau E, Tolbert LS, Kortepeter L, Pratt M, Nyakoe N, Muringo L, et al. Development of a highly sensitive genus-specific quantitative reverse transcriptase real-time PCR assay for detection and quantitation of Plasmodium by amplifying RNA and DNA of the 18S rRNA genes. J Clin Microbiol. 2011:49:2946-53.

36. Hendriksen ICE, Mtove G, Pedro AJ, Gomes E, Silamut K, Lee SJ, et al. Evaluation of a PfHRP2 and a pLDH-based rapid diagnostic test for the diagnosis of severe malaria in 2 populations of African children. Clin Infect Dis. 2011;52:1100-7.

37. Kilian AH, Metzger WG, Mutschelknauss EJ, Kabagambe G, Langi P, Korte $R$, et al. Reliability of malaria microscopy in epidemiological studies: results of quality control. Trop Med Int Health. 2000;5:3-8.

38. Mwingira F, Genton B, Kabanywanyi ANM, Felger I. Comparison of detection methods to estimate asexual Plasmodium falciparum parasite prevalence and gametocyte carriage in a community survey in Tanzania. Malar J. 2014;13:433.

39. WHO. Malaria rapid diagnostic test performance: results of WHO product testing of malaria RDTs: Round 5 (2013); 2014. https://www.apps.who. int/iris/bitstream/handle/10665/128678/9789241507554_engpdf;seque $n c e=1$. Accessed 2 Feb 2020.

40. Snounou G, Viriyakosol S, Jarra W, Thaithong S, Brown KN. Identification of the four human malaria parasite species in field samples by the polymerase chain reaction and detection of a high prevalence of mixed infections. Mol Biochem Parasitol. 1993;58:283-92.

41. Day KP, Marsh K. Naturally acquired immunity to Plasmodium falciparum. Parasitol Today. 1991;7:68-71.

42. Grobusch MP, Kremsner P. Uncomplicated malaria. In: Sullivan DJ, Krishna S, editors. Malaria: drugs, disease and post-genomic biology. Current topics in microbiology and immunology, vol. 295. Berlin: Springer; 2005. p. 83-104.

43. Snow RW, Omumbo JA, Lowe B, Molyneux CS, Obiero JO, Palmer A, et al. Relation between severe malaria morbidity in children and level of Plasmodium falciparum transmission in Africa. Lancet. 1997;349:1650-4.

44. Vafa M, Troye-Blomberg M, Anchang J, Garcia A, Migot-Nabias F. Multiplicity of Plasmodium falciparum infection in asymptomatic children in Senegal: relation to transmission, age and erythrocyte variants. Malar J. 2008;7:17.

45. Alves FP, Gil LHS, Marrelli MT, Ribolla PEM, Camargo EP, Da Silva LHP. Asymptomatic carriers of Plasmodium spp. as infection source for malaria vector mosquitoes in the Brazilian Amazon. J Med Entomol. 2005;42:777-9.

46. Baliraine Frederick N, Afrane Yaw A, Amenya Dolphine A, Bonizzoni M, Menge David M, Zhou G, et al. High prevalence of asymptomatic Plasmodium falciparum infections in a highland area of Western Kenya: a cohort study. J Infect Dis. 2009;200:66-74.

47. Bousema JT, Gouagna LC, Drakeley CJ, Meutstege AM, Okech BA, Akim INJ, et al. Plasmodium falciparum gametocyte carriage in asymptomatic children in western Kenya. Malar J. 2004;3:18.

48. Drakeley CJ, Akim NI, Sauerwein RW, Greenwood BM, Targett GA. Estimates of the infectious reservoir of Plasmodium falciparum malaria in The Gambia and in Tanzania. Trans R Soc Trop Med Hyg. 2000;94:472-6.

49. Noor AM, Kirui VC, Brooker SJ, Snow RW. The use of insecticide treated nets by age: implications for universal coverage in Africa. BMC Public Health. 2009;9:369.
50. Pullan RL, Bukirwa H, Staedke SG, Snow RW, Brooker S. Plasmodium infection and its risk factors in eastern Uganda. Malar J. 2010;9:2.

51. Bottius E, Guanzirolli A, Trape JF, Rogier C, Konate L, Druilhe P. Malaria: even more chronic in nature than previously thought; evidence for subpatent parasitaemia detectable by the polymerase chain reaction. Trans $\mathrm{R}$ Soc Trop Med Hyg. 1996;90:15-9.

52. Greenwood BM. Asymptomatic malaria infections-do they matter? Parasitol Today. 1987;3:206-14.

53. Laishram DD, Sutton PL, Nanda N, Sharma VL, Sobti RC, Carlton JM, et al. The complexities of malaria disease manifestations with a focus on asymptomatic malaria. Malar J. 2012;11:29.

54. Clarke SE, Jukes MCH, Njagi JK, Khasakhala L, Cundill B, Otido J, et al. Effect of intermittent preventive treatment of malaria on health and education in schoolchildren: a cluster-randomised, double-blind, placebocontrolled trial. Lancet. 2008;372:127-38.

55. Fernando SD, Rodrigo C, Rajapakse S. The "hidden" burden of malaria: cognitive impairment following infection. Malar J. 2010;9:366.

56. Lalloo DG, Olukoya P, Olliaro P. Malaria in adolescence: burden of disease, consequences, and opportunities for intervention. Lancet Infect Dis. 2006;6:780-93.

57. Nankabirwa J, Wandera B, Kiwanuka N, Staedke SG, Kamya MR, Brooker SJ. Asymptomatic Plasmodium infection and cognition among primary schoolchildren in a high malaria transmission setting in Uganda. Amer J Trop Med Hyg. 2013;88:1102-8.

58. Thuilliez J. Fever, malaria and primary repetition rates amongst school children in Mali: combining demographic and health surveys (DHS) with spatial malariological measures. Soc Sci Med. 2010;71:314-23.

59. Thuilliez J, Sissoko MS, Toure OB, Kamate P, Berthélemy JC, Doumbo OK. Malaria and primary education in Mali: a longitudinal study in the village of Donéguébougou. Soc Sci Med. 2010;71:324-34.

60. Agency for_International_Development. U.S. President's Malaria Initiative Democratic Republic of the Congo Malaria Operational Plan FY 2020; 2020. https:/www.pmigov/docs/default-source/default-document-libra ry/malaria-operational-plans/fy20/fy-2020-democratic-republic-of-thecongo-malaria-operational-plan.pdf?sfvrsn=6. Accessed on 6 Apr 2021

61. Brazeau NF, Whitesell AN, Doctor SM, Keeler C, Mwandagalirwa MK, Tshefu AK, et al. Plasmodium vivax infections in duffy-negative individuals in the Democratic Republic of the Congo. Am J Trop Med Hyg. 2018;99:1128-33.

62. Ferrari G, Ntuku HM, Schmidlin S, Diboulo E, Tshefu AK, Lengeler C. A malaria risk map of Kinshasa, Democratic Republic of Congo. Malar J. 2016;15:27.

63. Isozumi R, Fukui M, Kaneko A, Chan CW, Kawamoto F, Kimura M. Improved detection of malaria cases in island settings of Vanuatu and Kenya by PCR that targets the Plasmodium mitochondrial cytochrome $c$ oxidase III (cox3) gene. Parasitol Int. 2015;64:304-8.

64. Kazadi W, Sexton JD, Bigonsa M, W'Okanga B, Way M. Malaria in primary school children and infants in Kinshasa, Democratic Republic of the Congo: surveys from the 1980s and 2000. Am J Trop Med Hyg. 2004;71 (2 Suppl):97-102.

65. Coene J. Malaria in urban and rural Kinshasa: the entomological input. Med Vet Entomol. 1993;7:127-37.

66. Bomblies A. Modeling the role of rainfall patterns in seasonal malaria transmission. Clim Change. 2012;112:673-85.

67. Stresman GH. Beyond temperature and precipitation: Ecological risk factors that modify malaria transmission. Acta Trop. 2010;116:167-72.

68. Rodriguez-Barraquer I, Arinaitwe E, Jagannathan P, Kamya MR, Rosenthal PJ, Rek J, et al. Quantification of anti-parasite and anti-disease immunity to malaria as a function of age and exposure. Elife. 2018;7:e35832.

69. White M, Watson J. Age, exposure and immunity. Elife. 2018;7:e40150.

70. Woolhouse MEJ. Patterns in parasite rpidemiology: the peak shift. Parasitol Today. 1998; 14:428-34

71. Agency_for_International_Development. US. President's Malaria Initiative Democratic Republic of the Congo Malaria Operational Plan FY 2018; 2018. https://www.pmigov/docs/default-source/default-document-libra ry/malaria-operational-plans/fy-2018/fy-2018-democratic-republic-ofthe-congo-malaria-operational-plan.pdf?sfvrsn=5. Accessed 2 Dec 2020.

72. Mahittikorn A, Masangkay FR, Kotepui KU, Milanez GJ, Kotepui M. Comparison of Plasmodium ovale curtisi and Plasmodium ovale wallikeri infections by a meta-analysis approach. Sci Rep. 2021;11:6409. 
73. Fuehrer HP, Habler VE, Fally MA, Harl J, Starzengruber P, Swoboda P, et al. Plasmodium ovale in Bangladesh: genetic diversity and the first known evidence of the sympatric distribution of Plasmodium ovale curtisi and Plasmodium ovale wallikeri in southern Asia. Int J Parasitol. 2012;42:693-9.

74. Betson M, Sousa-Figueiredo JC, Atuhaire A, Arinaitwe M, Adriko M, Mwesigwa G, et al. Detection of persistent Plasmodium spp. infections in Ugandan children after artemether-lumefantrine treatment. Parasitology. 2014;141:1880-90.

75. Greenwood BM, Bradley AK, Greenwood AM, Byass P, Jammeh K, Marsh K, et al. Mortality and morbidity from malaria among children in a rural area of The Gambia, West Africa. Trans R Soc Trop Med Hyg. 1987;81:478-86.

76. Siala E, Khalfaoui M, Bouratbine A, Hamdi S, Hili K, Aoun K. Relapse of Plasmodium malariae malaria 20 years after living in an endemic area. Presse Med. 2005;34:371-2 (in French).

77. Bottieau E, Van Gompel A, Peetermans WE. Failure of primaquine therapy for the treatment of Plasmodium ovale malaria. Clin Infect Dis. 2005;41:1544-5.

78. Center_for_Disease_Control_and_Prevention. About Malaria; 2019. https://www.cdcgov/malaria/about/. Accessed 28 Nov 2020.

79. Chin W, Coatney GR. Relapse activity in sporozoite-induced infections with a West African strain of Plasmodium ovale. Am J Trop Med Hyg. 1971;20:825-7.

80. Collins WE, Jeffery GM. A retrospective examination of sporozoiteinduced and trophozoite-induced infections with Plasmodium ovale: development of parasitologic and clinical immunity during primary infection. Am J Trop Med Hyg. 2002;66:492-502.

81. Garnham PC, Bray RS, Cooper W, Lainson R, Awad FI, Williamson J. The pre-erythrocytic stage of Plasmodium ovale. Trans R Soc Trop Med Hyg. 1955;49:158-67.
82. Jeffery GM, Young MD, Wilcox A. The Donaldson strain of malaria. 1. History and characteristics of the infection in man. Am J Trop Med Hyg. 1954;3:628-37.

83. Nathwani D, Currie PF, Smith CC, Khaund R. Recurrent Plasmodium ovale infection from Papua New Guinea-chloroquine resistance or inadequate primaquine therapy? J Infect. 1991;23:343-4.

84. Facer CA, Rouse D. Spontaneous splenic rupture due to Plasmodium ovale malaria. Lancet. 1991;338:896.

85. Groger M, Fischer HS, Veletzky L, Lalremruata A, Ramharter M. A systematic review of the clinical presentation, treatment and relapse characteristics of human Plasmodium ovale malaria. Malar J. 2017;16:112.

86. Abdulraheem MA, Ernest M, Ugwuanyi I, Nishikawa S, Adeleke M, Orimadegun $A E$, et al. High prevalence of Plasmodium malariae and Plasmodium ovale in co-infections with Plasmodium falciparum in asymptomatic malaria parasite carriers in Southwest Nigeria. medRxiv. 2021. https://doi. org/10.1016/j.ijpara.2021.06.003.

87. Black J, Hommel M, Snounou G, Pinder M. Mixed infections with Plasmodium falciparum and P. malariae and fever in malaria. Lancet. 1994;343:1095.

88. Tang J, Templeton TJ, Cao J, Culleton R. The consequences of mixedspecies malaria parasite co-infections in mice and mosquitoes for disease severity, parasite fitness, and transmission success. Front Immunol. 2020;10:3072

\section{Publisher's Note}

Springer Nature remains neutral with regard to jurisdictional claims in published maps and institutional affiliations.
Ready to submit your research? Choose BMC and benefit from:

- fast, convenient online submission

- thorough peer review by experienced researchers in your field

- rapid publication on acceptance

- support for research data, including large and complex data types

- gold Open Access which fosters wider collaboration and increased citations

- maximum visibility for your research: over 100M website views per year

At BMC, research is always in progress.

Learn more biomedcentral.com/submissions 